\title{
Los trabajadores de la madera y el mueble de la ciudad de Buenos Aires. Conflictividad laboral, estructuración sindical e identidades políticas, 1900-1905
}

\section{Wood and furniture workers of Buenos Aires city. Labor unrest, trade union structure and political identities, 1900-1905}

\author{
Walter Ludovico Koppmann \\ Centro de Estudios Históricos de los Trabajadores y las Izquierdas \\ Instituto de Historia Argentina y Americana Dr. Emilio Ravignani \\ Consejo Nacional de Investigaciones Científicas y Técnicas \\ walter.koppmann@gmail.com
} (Argentina)

\section{Resumen}

El artículo examina la conflictividad laboral, las formas de organización sindical en los lugares de trabajo y el rol de las culturas políticas de izquierda en la rama de la madera y el mueble de la ciudad de Buenos Aires durante el primer lustro del siglo XX. En paralelo al desarrollo urbano ligado al puerto, se expandieron aquellos oficios madereros, cuyos contornos, tareas y atmósferas laborales fueron variables, condicionando diversas experiencias de inserción de las izquierdas entre estos trabajadores. A través de un análisis de la prensa gremial y política así como de la bibliografía especializada, se propone estudiar las diferencias organizativas entre los oficios con alta calificación y aquellos menos calificados así como los debates y planteos entre las distintas corrientes políticas (socialismo, anarquismo, sindicalismo). Apuntamos a contribuir al conocimiento sobre las acciones, debates y tensiones que atravesaron los trabajadores madereros en el período crítico del cambio de siglo mediante la investigación en profundidad sobre un sector industrial específico.

Palabras Clave: conflictividad laboral, formas de organización sindical, culturas políticas de izquierda, rama de la madera y el mueble. 


\begin{abstract}
The article explores the labor struggle, union workers organization in workplaces and the role played by political left cultures in the wood and furniture industry in Buenos Aires city, during the first years of the XXth century. Running parallel to the urban development connected to the port, wood industry trades expanded. In that regard, tasks and working environments kept changing as well, conditioning different political left experiences. Through an analysis of Union workers' journals, political press and specialized literature, we will study both organizational differences between skilled and unskilled workers and debates and arguments between different political left sectors (socialists, anarchists, revolutionary syndicalists). Through a deep research on wood workers, we aim to contribute to the knowledge about actions, debates and tensions that encountered this specific industry at the turn of the century.
\end{abstract}

Keywords: labor struggle, organizational union body forms, political left cultures, wood and furniture industry.

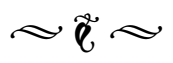

\section{Introducción}

En los últimos años, la producción historiográfica sobre el movimiento obrero argentino a principios del siglo $\mathrm{XX}$ se ha visto renovada por una serie de estudios tanto de autores jóvenes como de otros ya consolidados. En esta dirección, importantes trabajos han analizado los orígenes y la formación de la clase obrera (Falcón, 1984; Poy, 2014), los procesos de delimitación de las identidades de las llamadas "culturas políticas de izquierda" (Camarero, 2016), la inserción gremial del socialismo (Camarero y Herrera, 2005; Ceruso, 2017; Martínez Mazzola, 2011; Poy, 2016), las características de la militancia sindicalista (Belkin, 2018; Caruso, 2016) y la intervención anarquista, más allá de los trabajos ya clásicos (Anapios, 2016; Fernandez Cordero, 2015; Oved, 2013; Suriano, 2001). Menor impulso ha recibido, en cambio, la producción historiográfica que indaga la historia de los trabajadores en vinculación con la evolución industrial y el proceso de trabajo. En este punto, han sido analizados los casos de los obreros gráficos (Bill, 2007), de la carne (Lobato, 2001), del dulce (Scheinkman, 2016), metalúrgicos (Camarero y Ceruso, 2016), entre otros, mostrando la fecundidad de esta clase de enfoque.

Este artículo propone estudiar el caso de los trabajadores de la industria de la madera y el mueble de la ciudad de Buenos Aires, entre 1900 y 1905. Sólo unos pocos autores han abordado la temática y ninguno se ha situado en el comienzo del siglo XX. De esta manera, Villalba (2010), quien fuera dirigente del sindicato maderero, analiza su historia si bien desde una mirada institucional ("desde arriba”). Luego, se destaca el trabajo de Lizárraga y Mason (2016), ubicado en un período posterior aunque con datos significativos para este análisis. Asimismo, el artículo de Camarero y Ceruso (2015) provee un cúmulo de evidencia general e hipótesis que son puestas a prueba en este escrito. Por último, se retoman algunos de los interrogantes planteados en una publicación anterior, buscando profundizar en los primeros años del siglo XX (Koppmann, 2018). 
La hipótesis principal que guía este trabajo es que la rama de la madera y el mueble fue un sector de composición heterogénea (en términos de subsectores y oficios), con una importante gravitación en la producción de la ciudad de Buenos Aires de comienzos del siglo XX, ligada al ingente desarrollo urbano que tuvo lugar en estos años. De este modo, la complejidad resultante entre diferentes oficios con variada calificación, procesos productivos y atmósferas laborales disímiles supuso distintas experiencias de estructuración sindical y de organización política en vinculación con las culturas de izquierda. Así, el ciclo huelguístico iniciado en 1903 consolidó una variedad de repertorios de organización ${ }^{1}$ y formas de lucha, reforzando las fronteras que separaban cada subsector entre sí.

Este trabajo se propone, en primer lugar, analizar la fisonomía de la rama durante estos años. En segundo lugar, estudiar las características productivas y los ambientes laborales que circunscribían las identidades de oficio así como su relación con las culturas políticas de izquierda. Por último, investigar la participación de estos trabajadores en los conflictos laborales que se desarrollaron entre 1903 y 1905. $\mathrm{El}$ artículo apunta a contribuir a nuestro conocimiento sobre el vínculo entre el movimiento obrero y las izquierdas desde la perspectiva de un estudio de caso localizado en una rama industrial específica.

1. Hallamos de utilidad el concepto de "repertorio de organización”, operativizado por Camarero (2007) y Ceruso (2015) para dar cuenta de aquellas modulaciones tácticas que se derivaban de las estrategias adoptadas por cada una de las corrientes. Cabe remarcar la cercanía de esta categoría con el concepto de "repertorios de la acción colectiva" (repertoire of collective action), elaborado por Tilly (1995).

\section{El mundo de la madera de Buenos Aires a comienzos del siglo $\mathrm{XX}$}

En el cambio de siglo, la situación económica argentina, desde el punto de vista de sus clases dominantes, parecía prometedora. Con excepción del lustro subsiguiente a 1890, fueron años de crecimiento, impulsado fundamentalmente desde el exterior, a partir de miles de trabajadores inmigrantes, amplios flujos de capital extranjero y la disponibilidad de mercados foráneos donde colocar las exportaciones argentinas (Rock, 2001, p. 115). Para el sector propietario de grandes extensiones de campos, fueron tiempos de bonanza. Cierta reversión del ciclo económico circa 1894 y la expansión agrícola que se verificó a partir de 1895 posibilitaron un incremento de las exportaciones, acompañando el alza de los precios en el mercado mundial, lo que, a la postre, produjo una valorización del peso (Belini y Korol, 2012, p. 55). Este fenómeno nacional e internacional se reflejó en un empeoramiento de las condiciones de vida de la clase obrera al aumentar los precios de los artículos de primera necesidad y las tarifas de servicios públicos; en los lugares de trabajo, los empleadores buscaron reducir los salarios nominales, excusándose en la revaluación de la moneda nacional (Oddone, 1949, p. 63).

Como una deriva de este proceso, la crisis de 1890 generó una temprana industrialización (Rocchi, 2006, pp. 86-124). La suspensión del patrón oro, la devaluación monetaria y el incremento de aranceles con el objetivo de resolver la crisis fiscal provocaron un cambio en los precios relativos, alentando un proceso de sustitución de importaciones. En el cruce de siglos, se inició un ciclo de acelerada expansión industrial y la participación del sector en el PBI ascendió de un 15\%, entre 1900 y 1909 , 
a un 17\%, entre 1910 y 1919 (Belini, 2017, p. 65). En paralelo a la evolución exportadora del sector primario, el veloz ritmo de la urbanización porteña impulsó la actividad de la construcción, promoviendo distintas áreas, entre otras, aquella ligada con la producción de madera (Díaz Alejandro, 1970, p. 212). De forma idéntica a otras industrias (con excepción de los frigoríficos, las harinas y el tanino), el sector de la madera y el mueble basó su expansión durante este período en el mercado interno (Gerchunoff y Llach, 2010, p. 70).

A fines del siglo XIX, la madera era empleada en aspectos nodales del binterland porteño: para construir inmuebles y herramientas, pavimentar calles, en el amueblamiento, el transporte de sustancias y alimentos o, incluso, el transporte mismo, ya fuera terrestre o marí- timo, entre los rubros más salientes (Liernur, 2000, pp. 424-425). Al igual que el resto de la incipiente industria de la época, el mundo de la madera presentaba una fisonomía dominada por empresas de tamaño reducido, con escaso capital y personal. En los talleres se trabajaba bajo una estructura casi artesanal, donde el sistema de regimentación laboral era de carácter familiar y las reglas no estaban establecidas (Camarero y Ceruso, 2015, p. 3). Corresponde notar, sin embargo, la existencia de un puñado de fábricas que empleaban cientos de trabajadores y poderosas máquinas, con distintas secciones por oficio. Así, las empresas que importaban muebles finos, las constructoras de carruajes y los grandes establecimientos aserraderos (que solían realizar obras para el Estado) representaban los capitales más concentrados del sector.

Tabla 1. Evolución de la rama maderera entre 1892 y 1908

\begin{tabular}{llll}
\hline Especialidad & $\begin{array}{c}\text { Cantidad de } \\
\text { talleres }\end{array}$ & \multicolumn{1}{c}{ Especialidad } & $\begin{array}{c}\text { Cantidad de } \\
\text { talleres }\end{array}$ \\
\hline Aserraderos & 39 & Aserraderos & 124 \\
Baúles & 16 & Baúles y valijas & 55 \\
Billares & 8 & Billares & 17 \\
Carpintería & 743 & Carpinterías & 882 \\
Carruajes & 76 & Carruajes y rodados & 198 \\
Muebles & 68 & Muebles & 606 \\
Sillas & 27 & Sillas & 66 \\
Tallistas & 11 & Escultura & 88 \\
Tornerías & 40 & Tornerías & 65 \\
Tonelería & 39 & Tonelerías & 26 \\
\hline TOTAL & $\mathbf{1 . 0 6 7}$ & - & $\mathbf{2 . 1 2 7}$ \\
\hline
\end{tabular}

Fuente: elaboración propia a partir de Helguera (1893) y Argentina. Dirección de Comercio é Industria (1915). 
Una característica clave en la expansión de la industria maderera fue su baja dependencia del comercio exterior en relación a la importación de materia prima, herramientas e insumos, logrando su suministro en el mercado interno (Schvarzer, 1996). De cualquier modo, antes de 1914 el 35\% de los insumos del sector en actividades manufactureras provenían del exterior y ese porcentaje ascendía a $60 \%$ en rubros no fabriles (Lizárraga y Masón, 2016, p. 12). Si bien la comparación es aproximada (en función de las distintas metodologías empleadas por Helguera en 1892 y los censistas de 1908), la Tabla 1 permite ilustrar la destacada evolución de la rama entre ambos años.

Como se puede observar, aquellas sub-ramas ligadas con el consumo urbano masivo, como las mueblerías, los aserraderos, las casas de sillas y constructoras de carruajes se expandieron de forma espectacular: la producción de muebles se multiplicó casi por diez, la de carruajes creció casi tres veces e igual ocurrió con la ela- boración de sillas y los aserraderos. En cantidad de establecimientos, la rama se duplicó en el curso de quince años. Una observación sobre las sub-ramas principales permitirá entender mejor las jerarquías de cada especialidad dentro del sector.

Según se puede apreciar, los aserraderos ocupan la delantera dentro del conjunto, tanto en términos de capital como de ventas y fuerza motriz. Estas empresas junto con las carpinterías concentraban el $76,9 \%$ de la fuerza motriz, confirmando lo señalado acerca del carácter cuasi-artesanal de la producción del sector, en particular la mueblera. En términos comparativos, según el censo nacional de 1914, el establecimiento medio en Argentina ocupaba un promedio de 8,4 personas, utilizando 13,9 HP de fuerza motriz, aproximándose a lo que era el taller de un sastre o de un zapatero (Bilsky, 2011, p. 43). En relación a la magnitud del valor de las ventas, resaltan los casos de las casas de tornería y escultura, las cuales aún

Tabla 2. Principales sub-ramas del mundo de la madera

\begin{tabular}{llllll}
\hline Clasificación & $\begin{array}{l}\text { Número de } \\
\text { fábricas y talleres }\end{array}$ & $\begin{array}{l}\text { Capital en } \\
\mathbf{\$ m} / \mathbf{n}\end{array}$ & $\begin{array}{l}\text { Venta anual } \\
\text { en } \mathbf{\$ m} / \mathbf{n}\end{array}$ & $\begin{array}{l}\text { Fuerza } \\
\text { motriz }(\mathbf{H P})\end{array}$ & Personal \\
\hline Aserraderos & 124 & 6.575 .555 & 18.051 .480 & 3.452 & 2.994 \\
Carpinterías & 882 & 3.823 .585 & 13.250 .260 & 1.225 & 4.159 \\
Carruajes y rodados & 198 & 1.859 .015 & 5.537 .645 & 400 & 1.549 \\
Escultura & 88 & 333.540 & 1.326 .192 & 37 & 432 \\
\hline Mueblerías & 606 & 3.721 .940 & 10.846 .590 & 570 & 3.107 \\
Tornerías & 65 & 424.585 & 994.070 & 397 & 341 \\
\hline TOTAL & $\mathbf{1 . 9 6 3}$ & $\mathbf{1 6 . 7 3 8 . 2 2 0}$ & $\mathbf{5 0 . 0 0 6 . 2 3 7}$ & $\mathbf{6 . 0 8 1}$ & $\mathbf{1 2 . 5 8 2}$ \\
\hline
\end{tabular}

Fuente: elaboración propia a partir de Argentina. Dirección de Comercio é Industria (1915). 
siendo unas pocas decenas, presentaban valores cercanos o mayores al millón de pesos (no obstante corresponde resaltar que los talleres de escultura de mármol, piedra u otro material no estaban diferenciados de aquellos de talla de madera). Esto último podría indicar el alto valor agregado de la sub-rama así como la necesaria calificación de los escultores (rayando lo artístico) además de que su consumo estaba destinado exclusivamente a las clases altas. Finalmente, cabe destacar el bajo número de obreros por establecimiento (en promedio), figurando los aserraderos como los lugares donde había una mayor concentración (24 obreros) frente a los bajos valores de las mueblerías (5 trabajadores). No dejan de ser llamativas las cifras totales relativas a la rama en su conjunto: varias decenas de miles de trabajadores desperdigados por toda la ciudad, empleados en disciplinas y labores disímiles. Con más de 10.000 trabajadores, el sector representaba una de las poblaciones obreras más importantes de la ciudad, detrás de los ferroviarios y los marítimos, siendo los madereros de la construcción quienes aportaban el mayor contingente al total.

\section{Izquierdas, organización sindical e identidades de clase}

Una de las características más sobresalientes en el análisis de la rama durante las primeras décadas del siglo XX fue la profusa intervención de la totalidad de las corrientes de izquierda a través de un repertorio de organización variado, significativos debates y una permanente iniciativa militante. Así, la presencia de socialistas y anarquistas en el mundo de la madera fue abundante desde finales del siglo XIX (Koppmann, 2018). Ahora bien, ¿qué vínculo podría establecerse entre el proceso de trabajo, la calificación del oficio y las formas de estructuración sindical? ¿Qué relaciones pueden plantearse, a su vez, entre estas esferas y el papel de las culturas políticas de izquierda?

En el transcurso de la primera década del siglo XX y hasta circa 1914, la expansión urbana de Buenos Aires y las necesidades de productos y servicios que se derivaban de este proceso impulsaron el crecimiento del conjunto de los oficios madereros. De este modo, la etapa que se abrió en 1903, con su reguero de huelgas y grandes luchas sociales hasta el año 1906 inclusive, implicó la consolidación de las formas de estructuración sindical de los madereros, desde los gremios más calificados (ebanistas, constructores de carruajes y carros, escultores, torneros) hasta aquellos menos calificados (aserradores, carpinteros, peones), luego de un período anterior que se había distinguido por el repliegue organizativo y de la movilización obrera en general. Para vincular esta dimensión relativa al proceso de trabajo con las formas de organización sindical, hallamos de utilidad el concepto de "autonomía artesanal" (Montgomery, 1979, p. 10), que define la capacidad de dominio sobre el proceso laboral no como un estado de cosas que existió en algún momento determinado sino como una batalla crónica que asumió una variedad de formas, la primera de las cuales era la autonomía del obrero-artesano que aún no ha sido subyugado por la "gran industria" capitalista y que, por ende, habilitaba cierto poder de resistencia frente a los deseos de sus empleadores.

Entre los trabajadores madereros con mayor calificación, su conocimiento del oficio y de los secretos artesanales en un medio escasamente maquinizado constituía un serio desafío desde el punto de vista patronal a la hora de entablar 
los conflictos laborales ya que los rompehuelgas, según la mayoría de los registros, desconocían las labores y acababan por arruinar los trabajos. ${ }^{2}$ En otras palabras, la "autonomía artesanal" dificultaba que los propietarios pudieran reemplazar fácilmente a los huelguistas. Por esta razón, para un oficial calificado no tenía demasiado sentido lanzarse a un movimiento general sin la adecuada preparación y cuyo final era incierto, resultando mucho más sencillo realizar huelgas parciales. En gremios de estas características, la declaración de la huelga general se emparentaba con un argumento de carácter político, frecuentemente esgrimido desde los sectores anarquistas. Así, esta suerte de "talismán" (skilled work) determinó una particular dinámica de los conflictos en los talleres constructores de carruajes así como, en especial, en las mueblerías de la Buenos Aires de principios del siglo XX, donde la posibilidad de negociar con los capitalistas en mejores condiciones y de acordar un marco de explotación de la fuerza de trabajo percibido como más "ventajoso", se configuró como un campo fértil para el desarrollo de una experiencia político-gremial conectada con las expresiones tácticamente más moderadas dentro del movimiento sindical, cuyo representante paradigmático fue, en un primer momento, el Partido Socialista (en adelante, PS).

En efecto, su visión "evolucionista” sobre la lucha de clases, donde el conflicto se desataba como producto del desentendimiento entre trabajadores y patrones, se vio favorecida por las condiciones generales de producción y la atmósfera de "respetabilidad" que rodeaban la actividad en la rama. Por otro lado, un aspecto

2. Malfatto, L. (abril y mayo de 1906). Nuestro último triunfo. El Obrero Ebanista, 12. Biblioteca del Sindicato de Obreros en Madera de la Capital Federal, Buenos Aires. que no debe ser subestimado es la consideración del PS acerca de los "talleres cooperativas", que emergieron en algunas coyunturas (como a fines del siglo XIX) y para ciertos oficios muy especializados (como los toneleros o los escultores), experiencias toleradas e incluso impulsadas por militantes socialistas. ${ }^{3}$ Años más tarde, con la emergencia del sindicalismo como corriente predominante entre los ebanistas, las cooperativas serían duramente criticadas, asimilándolas a la tendencia de los obreros a volverse patrones. ${ }^{4}$ Cabe añadir que el universo subyacente a las ilusiones de ascender socialmente alimentaba las relaciones laborales en los "boliches" (pequeños talleres), donde la lengua del self-help, el paternalismo y el énfasis en el trabajo duro, la fuerza de voluntad, el ahorro y la educación formaban un todo inescindible (Gandolfo, 1992, p. 319). La tendencia a establecer talleres de forma cooperativa, asimismo, reapareció a posteriori con mayor asiduidad entre los gremios "artísticos" (por sus dimensiones, labores y nivel de especialización) como los escultores, los torneros y los marqueteros.

En cualquier caso, sobresalen en el análisis los límites que encontró la inserción del PS no sólo en la industria maderera sino, antes bien, en el conjunto del movimiento sindical argentino (Camarero y Herrera, 2005). Por el contrario, los clivajes apolíticos y obreristas presentes en la discursividad sindicalista permitieron superar a los socialistas hacia $1905 \mathrm{y}$ afianzar su arraigo entre la masa obrera del sector, propensa a organizarse de forma compacta

3.Ebanistas (4 de diciembre de 1897). La Vanguardia. Biblioteca Popular Juan B. Justo, Buenos Aires. Toneleros (8 de enero de 1898). La Vanguardia. Constructores de carruajes (1 de septiembre de 1900). La Vanguardia.

4. Dividendo, cooperativa o centurión (noviembre de 1919). El Obrero Ebanista, 89. 
por reivindicaciones inmediatas en los lugares de trabajo, y no tanto así por desarrollar una actividad de carácter electoral-parlamentaria, como entendía la lucha política a grandes rasgos el PS. A su vez, un elemento no menor que ayudó al ascendiente del sindicalismo revolucionario entre los ebanistas en particular fue la preeminencia dada al organismo sindical en tanto eje ordenador de la lucha de clases, siendo bastante natural para los obreros el hecho de pertenecer a la "familia sindical". ${ }^{5}$ En efecto, la afiliación sindical posibilitaba mejores condiciones de compra-venta de su fuerza de trabajo en el marco de sitios laborales con baja densidad de empleados, donde la cercanía social y étnica con los patrones podía ser alta. Por último pero no menor, a diferencia de los establecimientos constructores de carruajes o de carros, donde se enlazaban oficios heterogéneos (aunque todos altamente especializados), los ebanistas y sus disciplinas conexas formaban un colectivo mucho más homogéneo en el plano productivo.

Estamos en presencia, por lo tanto, de un sector económico con alta calificación, cierto dominio sobre el proceso de trabajo y un amplio margen de maniobra al momento de desenvolver los conflictos laborales y de negociar las condiciones de explotación de la fuerza de trabajo. El oficio, situado en un punto intermedio entre la cooperación y la manufactura, representaba un eje esencial en torno al cual se desplegaban un conjunto de estructuras y de disposiciones subjetivas. El proceso productivo requería cierto acervo cultural, tanto en el terreno estético como incluso en el dominio del cálculo y la geometría. El hecho de que el ebanista y el constructor de carruajes tuvieran que

5. Cuomo, J. Sindicatos obreros (septiembre de 1905). El Obrero Ebanista, 8.

8 llevar su propio banco y herramientas reforzaba la figura del obrero-"artista" y se entremezclaba con un relativo dominio de la producción por parte del trabajador, donde el cuidado por el detalle era decisivo (Patroni, 1897). Estos elementos conjugaron una atmósfera laboral característica, donde el oficio operaba como una variable "dignificante", cimentando cierto orgullo al formar parte del colectivo obrero y, por lo tanto, actuando como una vía de distinción social que configuraba un determinado "código de ética" (Montgomery, 1979, p. 12). ${ }^{6}$

Como resultado del profuso vínculo entre trabajadores y culturas políticas de izquierda, desde los comienzos de la organización gremial ebanista circa 1896, se observa una relativa solidez del proceso de estructuración sindical, vehiculizado mediante la importancia atribuida a la organización y la elección de delegados en los sitios laborales, el cuidado por las cotizaciones y las finanzas del sindicato, el rol y difusión de la prensa gremial (primero La Organización, luego El Obrero Ebanista), las actividades culturales y, por último pero no menor, el papel desempeñado por las reuniones $\mathrm{y}$ asambleas periódicas. Todos estos elementos destacaron al sindicato ebanista como una de las principales formaciones sindicales durante el primer cuarto de siglo.

En relación al segundo conjunto de oficios, aquellos con menor calificación, cabe mencionar como un hito significativo en su trayectoria organizativa, en paralelo con la expansión del anarquismo "organizador" en los gremios, la fundación del sindicato de carpinteros,

6. El "código de ética", derivado de la llamada "autonomía artesanal", modelaba la conducta de estos trabajadores, los contornos que asumía la organización gremial y las formas de contralor obrero en el ámbito laboral (Montgomery, 1979, p. 14). 
en julio de 1902. Afiliado de inmediato a la Federación Obrera Argentina (en adelante, FOA), ${ }^{7}$ se trató del primer paso firme dado por los libertarios en el mundo de la madera en pos de combatir el predominio socialista que, como vimos, aparecía apuntalado entre los ebanistas y sus oficios anexos así como entre los constructores de carruajes. En el caso del sindicato carpintero, su principal contingente de trabajadores provenía de los trabajadores oficiales empleados en las obras de construcción (cuya calificación era alta en relación a cualquier peón pero bastante menor que la de un ebanista), los cientos de obreros que trabajaban en talleres de "carpintería mecánica" (o carpintería a secas) -de tamaño variado- y el conjunto amorfo de peones sin calificación. En este punto, corresponde señalar el constante celo del gremio ebanista por diferenciarse de los carpinteros, en una actitud de carácter corporativa que se prolongó durante años y cuya única justificación radicaba en que los primeros solían producir mayormente para la industria del mueble mientras que los segundos se vinculaban con el rubro de la construcción (sea edificando, sea preparando partes o elaborando la madera). De cualquier manera, en muchos casos y dependiendo de la coyuntura, ambos oficios, talleres y labores aparecían entremezclados y las fronteras, por ende, se diluían; en tiempos de crisis, era común la movilidad de obreros entre sub-ramas. ${ }^{8}$

7. La FOA cambió su nombre a Federación Obrera Regional Argentina (en adelante, FORA) en su IV congreso, realizado en agosto de 1904, cuando se estableció como principio estatutario el "comunismo anárquico" (Oved, 2013).

8. Federación de trabajadores en madera de la República Argentina (abril y mayo de 1906). El Obrero Ebanista, núm. 12
Entre los carpinteros, existían varias representaciones sindicales ya que, al tratarse de un oficio "genérico", contaba con especializaciones diversas, pudiendo variar entre una amalgama de lugares de trabajo, procesos productivos y patronales sumamente heterogéneo: pequeños y medianos talleres de carpintería civil; "carpinteros de ribera" de los aserraderos y astilleros; en los establecimientos municipales del Riachuelo, talleres del ferrocarril así como de los tranvías; a bordo de los navíos, construyendo corrales para animales; en las obras de construcción.

Al tratarse de oficios con baja calificación, este sector se veía forzado a establecer algún tipo de alianza con otros trabajadores en momentos de conflictos prolongados. Según cada oficio, el marco de alianzas podía variar. No obstante, en casi todos los casos los conductores de carros podían precipitar una derrota, sea traicionando la huelga, ya sea siendo ellos mismos reemplazados; idéntica función se verificaba con respecto a los obreros aserradores y estibadores en los paros dentro de los corralones de materiales. ${ }^{9}$ Entre los carpinteros de ribera y quienes trabajaban en los talleres ferroviarios y tranviarios, era decisivo el apoyo de otras secciones del lugar así como también de la estructura sindical del sector macro al cual respondían (marítimos, ferroviarios, tranviarios respectivamente). A partir del problema de las alianzas, es factible pensar que la versatilidad de las formas de lucha y estructuración sindical de los libertarios empalmaba mejor frente a este "requerimiento" táctico y en gremios cuyo reemplazo por rompehuelgas era practicable, hecho que producía álgidas confrontaciones

9. Huelgas. Carpinteros y anexos (sección Boca) (10 de enero de 1906). La Vanguardia. 
físicas. ${ }^{10}$ Sobre el particular, un rasgo distintivo de las acciones impulsadas por los anarquistas era el recurso permanente a la "acción directa" (huelgas, boicots, sabotaje, empleo de la violencia), entendida como un aspecto que le daba "expresividad", "energía" al conflicto social, en contraste con las huelgas impulsadas por el PS (y en parte por los sindicalistas), donde su característica central era "quedarse de brazos cruzados”, como afirmaban los críticos ácratas, ya sea pagando subsidios a los huelguistas, ubicándolos en otros talleres, entre otras formas. ${ }^{11}$

Si en el sector del mueble y parte de la carpintería civil los talleres solían pertenecer a un patrón mediano-pequeño, con excepción de algunas grandes fábricas de origen extranjero (Thompson, Maple, etc.), en el caso de los talleres mecánicos-aserraderos, los astilleros y las empresas de construcción (junto con los contratistas), se trataba de capitales mucho más concentrados, radicados en establecimientos dominados por un sistema de máquinas que condicionaba el proceso productivo $\mathrm{y}$, por lo tanto, las posibilidades y formas de resistencia de los trabajadores, debiendo ser mencionada, además, la amplia propensión a los accidentes, en muchos casos, fatales (las caídas en la construcción, las amputaciones entre los aserradores, etc.). ${ }^{12}$ Por lo tanto, la violencia obrera propiciada por los anarquistas podía aparecer como una consecuencia "lógica" de la regimentación establecida por un empresariado pode-

10. Véase, por ejemplo, el asesinato de un capataz durante una huelga ocurrida en el aserradero Drysdale. En lo de Drysdale (30 de septiembre de 1906). La Protesta. Biblioteca Popular José Ingenieros, Buenos Aires.

\section{Movimiento obrero (1 de abril de 1904). La Protesta.}

12. Martirologio obrero (4 de mayo de 1906). La

Protesta. Accidentes del trabajo (8 de agosto de 1906). La Vanguardia. Accidente del trabajo (21 de marzo de 1907). La Vanguardia. roso, emparentándose bastante en este punto con la dinámica de la conflictividad laboral portuaria (Caruso, 2016). En muchos establecimientos, predominaba una suerte de "espíritu de obraje”, donde el mando despótico del capataz y del director industrial (especie de gerente de fábrica) así como el ritmo de producción actuaban como mecanismos reguladores y disciplinadores, dificultando la organización en el sitio laboral. Los gritos y maltratos del capataz (hasta físicos, en el caso de los menores), las máquinas en el centro del proceso productivo, la nula libertad de acción al trabajar, los accidentes cotidianos y las jornadas prolongadas eran algunos de los elementos preponderantes en el universo laboral de estos trabajadores con menor o nula calificación. Esta clase de situaciones, si bien no deben en absoluto descartarse para el otro grupo (menos aún en períodos de crisis y de retroceso de la estructuración sindical), eran por lo pronto ajenas al horizonte de un obrero ebanista o de un constructor de carruajes.

Es menester destacar cómo, en un caso, los ebanistas tenían cierto dominio sobre el proceso productivo, pudiendo por ejemplo charlar entre sí o fumar mientras que, en el otro, la figura del capataz marcando de forma constante el ritmo de trabajo impedía cualquier tipo de intercambio. Esto no implica, no obstante, que no existieran reglamentos ni gerentes/capataces/directores en las mueblerías; al contrario, las casas más importantes como Thompson o Maple llegaron a tener varias secciones de fábrica con uno o varios supervisores así como severos reglamentos. La diferencia con los aserraderos radicaba, antes bien, en que en estos últimos el ritmo del trabajo y su cantidad signaban el carácter del proceso productivo por sobre la destreza individual del "obrero-artesano”. En términos equivalentes dentro de los 
carpinteros de la industria de la construcción, la necesidad de terminar la obra "a tiempo" (e incluso antes) se cumplimentaba sobre los esfuerzos y la sobre-explotación de los trabajadores, de los cuales se demandaba premura y eficiencia antes que cuidado artístico.

Un hecho decisivo, que separaba a los militantes anarquistas de los socialistas y también de los sindicalistas, eran sus esfuerzos por organizar al ejército de peones y demás oficios sin calificación; integrados en amplia proporción por jóvenes, eran el último eslabón en la cadena de explotación, recibiendo el maltrato tanto de capataces como de otros obreros. El fenómeno del ultraje de menores en los lugares de trabajo no era algo específico del mundo maderero ${ }^{13} \mathrm{y}$ tenía otras razones -además de la etaria-, que se vinculaban con una larga tradición artesanal de sometimiento y castigos a los aprendices y peones, según analiza Darnton (1984) para el caso de los tipógrafos franceses.

Al momento de reflexionar sobre una posible identidad maderera en el caso de este segundo grupo de oficios, asoman ciertas diferencias con respecto a los oficios calificados por lo que creemos correspondería hablar de identidades en plural antes que en singular. Un primer aspecto peculiar de los trabajadores con menor calificación era que, en virtud de tener que trazar alianzas tácticas con otros oficios, tendía a desdibujarse aquella matriz "corporativista", como sucedía, por el contrario, entre los ebanistas, cuyas "alianzas", en todo caso, consistían en subsumir los reclamos de los oficios adyacentes. En cambio, si en una obra en construcción los oficiales carpinteros paraban, era probable que los albañiles y yeseros se solidari-

13. Véase para el caso de la industria del dulce, por ejemplo: Scheinkman (2016). zaran, no ocurriendo necesariamente lo mismo si el detonante eran los peones. En segundo lugar, la premura requerida para finalizar la labor, la vigilancia sobre el ritmo y cantidad de producción (productividad) y la regimentación que recaía sobre un carpintero o un aserrador era muy disímil cuando se la compara con el control laboral dentro de un establecimiento ebanista o de construcción de carruajes: mientras que en los primeros se demandaba cantidad y rapidez, en los segundos se premiaba la calidad, el detalle y la virtud artística del obrero-artesano.

En síntesis, hemos señalado las características contrastantes entre uno y otro grupo, divididos según la calificación laboral, remarcando las diferencias existentes en la esfera productiva y en el terreno organizativo. A partir del análisis sobre las formaciones políticas que intervenían en el mundo de la madera y las identidades resultantes, a continuación se examinarán las huelgas y conflictos en el período que va desde 1900 hasta la declaración del estado de sitio, en febrero de 1905.

\section{Conflictividad laboral del mundo maderero, 1900-1904}

La situación de la clase trabajadora en Buenos Aires hacia 1900 era sumamente crítica. Entre 1869 y 1904 , la ciudad había quintuplicado su población, lo cual conllevó serios desequilibrios en la vida cotidiana con relación a la infraestructura y la movilidad urbanas (Rapoport y Seoane, 2007, p. 28). Junto con las penosas condiciones habitacionales (Yujnovsky, 1983), la falta de trabajo era otra de las dimensiones observables en el cambio de siglo. En julio de 1899, un cronista de La Prensa, llegó 
a afirmar que los desocupados no bajaban de 40.000 (Marotta, 1960, p. 101). En una mirada de conjunto sobre la conflictividad laboral en el mundo de la madera, si los años desde la recuperación económica circa 1894 hasta 1896 estuvieron marcados por una reorganización sindical y un abanico de luchas reivindicativas, el período transcurrido entre 1898 y 1903 apareció signado, en cambio, por el reflujo de la movilización obrera, sustrayéndose muchos de los logros conseguidos y empeorando las condiciones de trabajo en los talleres. ${ }^{14}$ Entre los ebanistas, los patrones argumentaban que la "mala situación" del gremio (es decir, el desempleo) se debía a la huelga declarada en 1897. En el caso de los grandes establecimientos aserraderos, la etapa se caracterizó por la agudización del proceso de concentración y centralización de capitales y por el incremento en la composición orgánica de los mismos, no obstante también se instalaron nuevas empresas al compás del crecimiento del puerto y sus necesidades de logística comercial (Patroni, 1897). Varios empresarios, en particular quienes destinaban sus productos al consumo de la alta sociedad, se volvieron importadores; fue el caso de los vendedores de carruajes, que comenzaron a importar carruajes desde Europa (Italia y Francia). ${ }^{15}$ En síntesis, entre 1898 y 1903, mermó el nivel de conflictividad laboral en la rama, se reimplantaron el destajo y el trabajo nocturno, proliferó el empleo de menores de edad (sobre todo en los boliches y aserraderos) y se vulneró la jornada de ocho horas. ${ }^{16}$

14. Para un análisis general sobre el período formativo del movimiento obrero argentino entre 1888 y 1896, véase Poy (2014).

15. Industria nacional (17 de junio de 1899). La Vanguardia.

16. Movimiento gremial (25 de febrero de 1899). La Vanguardia.

12
Aunque no de forma inmediata, a principios de 1901 se verificaron algunas iniciativas desde distintos sectores obreros frente al panorama circundante de crisis económica y miseria social, traduciéndose en una serie de conflictos laborales y violentas huelgas que acontecieron en el puerto de Buenos Aires y luego se extendieron con otros paros de actividades entre los sombrereros, los cigarreros, los tipógrafos y los panaderos, obteniendo resultados disímiles (Marotta, 1960). A comienzos de 1902, el epicentro de la protesta fue nuevamente el área portuaria y los barrios populares aledaños, La Boca-Barracas, involucrando a las obreras alpargateras, luego a los caldereros y mecánicos del taller Mihanovich, a los estibadores del puerto y a los trabajadores de las obras del Riachuelo, entre los cuales había decenas de carpinteros. ${ }^{17}$ Para este momento, un clima de creciente "histeria anti-anarquista" inundó la llamada opinión pública, concomitante a la propagación de la actividad libertaria en el seno de los gremios obreros (Oved, 2013, p. 211).

Sobre este mar de fondo puede situarse la huelga sucedida a comienzos de 1902 en el aserradero a vapor de Merlo, donde se empleaban decenas de menores de edad. Según se consignaba en una crónica, "hay niños de 10 a 12 años y se les hace trabajar 10 horas diarias, pagándoles de 5 a 9 centavos por hora", además de estar obligados a concurrir los domingos durante 4 horas para limpiar el taller, so pena de pagar una multa de $\$ 2$. Los reclamos de los "muchachos", por otra parte, eran modestos: un centavo de aumento por hora, el pago del trabajo dominical y la abolición de

17. El movimiento obrero de la boca del Riachuelo (enero de 1902). La Organización Obrera, 6. Centro de Documentación e Investigación de las Culturas de Izquierda (Cedinci), Buenos Aires. 
las multas; se informaba, además, que la policía había detenido a varios huelguistas. ${ }^{18} \mathrm{El}$ empleo de menores de edad en los aserraderos era generalizado, realizando las tareas más riesgosas, las cuales no pocas veces terminaban en accidentes fatales. El trabajo infantil cumplía varias funciones y en distintos planos: para los propietarios, permitía reducir los costos de trabajo así como preparar nuevos trabajadores a futuro de forma barata; a los obreros adultos les servía para desembarazarse de aquellas tareas más arriesgadas o pesadas (limpiar máquinas y pisos, cambiar correas, descargar madera) $y$, por añadidura, contar con un chivo expiatorio frente al capataz y la patronal; para la familia obrera, el mísero jornal de los menores era un complemento necesario de los reducidos ingresos del hogar. ${ }^{19}$

En cualquier caso, la actividad huelguística en el mundo de la madera durante 19011902 fue prácticamente nula, a contramano en cierto modo del ciclo general del movimiento obrero porteño, donde la constante represión estatal como respuesta frente a las demandas laborales fermentó el "contagio" entre los establecimientos y la lucha entre las clases escaló en intensidad, resultando una verdadera ola de conflictos. Hacia el mes de octubre de 1901, emergió un paro de actividades entre los peones de barracas y del mercado central de frutos que concitó la huelga solidaria de los estibadores y los conductores de carros. A mediados de noviembre, el gobierno de Roca decidió movi-

18. Última hora (11 de enero de 1902). La Vanguardia.

19. Según un informe posterior del Departamento Nacional del Trabajo (creado en 1907), "En la ciudad de Buenos Aires, la única razón para que las mujeres y los niños trabajen, radica en la insuficiencia del presupuesto de ingresos". Boletín del Departamento Nacional del Trabajo, 21, noviembre 1912, p. 312. Ministerio del Interior de la Nación, Buenos Aires. lizar las tropas del ejército, lo cual no implicó la reanudación de las actividades pero sí tensó los ánimos y unificó el repudio obrero en una destacadísima huelga general que, según se analizará, resultó un punto de inflexión dentro de las corrientes de izquierda. ${ }^{20} \mathrm{El} 23$ de noviembre, la ciudad continuaba paralizada y la conflictividad había alcanzado a los panaderos, zapateros, albañiles, sombrereros, fideeros, fosforeros, tejedores, mecánicos y fundidores, en el marco de un clima insurreccional que se había extendido a los puertos de Bahía Blanca, La Plata, Rosario y Villa Constitución (Oved, 2013, p. 220).

En este contexto, el Partido Socialista encomendó "moderación" y, si bien apoyó las huelgas de los oficios aledaños al mercado de frutos, desautorizó en cambio el paro del resto de los gremios (la "huelga general"), mandatando a una comisión integrada por el tornero Eneas Arienti, Francisco Cúneo y Celindo Castro para entrevistarse con el presidente Roca. Como es sabido, estas negociaciones nunca sucedieron y el gobierno envió al Congreso la Ley de Residencia (4.144) en la madrugada del 23 de noviembre, logrando su aprobación en escasas horas. Significativamente, el mismo día varios gremios realizaron asambleas para decidir si declaraban la huelga general contra este estado de cosas, entre otros, el sindicato de ebanistas, que votó rechazar la medida. ${ }^{21}$ En la misma dirección, el Comité de Propaganda Gremial (en adelante, CPG) surgido en el seno del PS, un organismo de naturaleza obrera impulsado por los constructores de carruajes $\mathrm{y}$ al cual se sumaron los ebanistas en noviembre de 1901, se negó a llamar a la huelga ge-

20. La huelga general de Buenos Aires (11 de enero de 1903). La Protesta Humana.

21. Al pueblo (29 de noviembre de 1902). La Vanguardia. 
neral y adhirió a la manifestación de protesta organizada por el PS contra el cercenamiento de las libertades democráticas y el estado de sitio. $^{22} \mathrm{El} \mathrm{CPG}$ reapareció varias veces en la historia del socialismo, dando cuenta de un proyecto que encarnaba en la necesidad de que el PS contara con una estrategia definida en el terreno de la lucha sindical, explicitando por otra parte la tensión subyacente entre los sectores más "orgánicos" con la línea parlamentarista del partido y aquellos más "obreristas" así como la marcada escisión entre lucha política y lucha gremial (Camarero, 2015; Tortti, 2007). Los socialistas finalmente quitaron cualquier apoyo a la huelga y el resultado acabó siendo negativo, frente a lo cual los anarquistas denunciaron al PS por "traidores". ${ }^{23}$

Como dijimos, la conflictividad laboral en el mundo de la madera recién recuperaría un sentido ascendente hacia 1903 y lo haría a partir de la organización del grupo de trabajadores sometido a las peores condiciones. Así, los primeros intentos de organización entre los obreros aserradores datan de noviembre de 1903, cuando se fusionaron con el sindicato libertario de carpinteros, formando la "Sociedad de Aserradores, Carpinteros y Anexos de La Boca y Barracas"; esta unidad organizativa, no obstante, duró muy poco tiempo. La cercanía con la actividad portuaria, donde el ascendiente libertario era alto, facilitó la militancia ácrata y, por ende, los carpinteros navales y de obra blanca así como los obreros aserradores tendieron a estrechar fuertes vínculos con el anarquismo (Santillán, 1927).

22. El estado de sitio y el Partido Socialista (29 de noviembre de 1902). La Vanguardia.

23. Los eternos judas (11 de enero de 1903). La Protesta Humana.

14
Al mes siguiente, alrededor de 4.500 obreros de estos oficios paralizaron las actividades, exigiendo $20 \%$ de aumento salarial, jornada de 8 horas y la ocupación "preferencial" de los obreros sindicalizados. ${ }^{24}$ Como en otras ocasiones, las asambleas se celebraban a diario. $\mathrm{Al}$ cabo de tres semanas, el 8 de enero de 1904 los carpinteros y aserradores acordaron con los patrones un salario mínimo de $\$ 3,50$ y la jornada de 8 horas por cuatro meses, 9 otros cuatro y 10 los restantes. ${ }^{25}$ En La Protesta se informaba también del paro de actividades que realizaron los obreros del puerto Madero (entre los cuales habían caldereros y carpinteros), reclamando aumento salarial y una jornada de 9 horas, así como de la agitación huelguística entre los obreros carpinteros de Dock Sud. ${ }^{26}$ Al movimiento reivindicativo se sumaron los toneleros, reclamando un aumento salarial del $15 \%$ y una jornada de 10 horas. Al cabo de unos pocos días, 24 patrones habían aceptado. ${ }^{27}$ Eran tiempos de reorganización gremial: a mediados de 1903, se constituyó la Sociedad de Obreros Escoberos en el local socialista de la circunscripción $11^{\circ}$, lanzándose a una huelga general en febrero de $1904 .{ }^{28} \mathrm{~A}$ fines de noviembre de 1903, se puso en pie la Sociedad Obreros Silleteros. ${ }^{29}$

24. Movimiento obrero (19 de diciembre de 1903). La Protesta.

25. Movimiento obrero (19 de diciembre de 1903). La

Protesta.

26. Movimiento obrero (19 de diciembre de 1903). La

Protesta.

27. Huelgas ganadas. Toneleros (2 de enero de 1904). La Vanguardia.

28. Huelgas ganadas. Obreros escoberos (27 de febrero de 1904). La Vanguardia.

29. Obreros silleteros (9 de enero de 1904). La Vanguardia. 
Con estos importantes antecedentes, la espiral huelguística en el mundo de la madera prosiguió en 1904, cuando 1.500 obreros ebanistas votaron ir a la huelga general, exigiendo la jornada laboral de 8 horas así como la prohibición del destajo, las horas extras y el trabajo los días festivos (incluyendo el $1^{\circ}$ de mayo); pedían, además, que se impidiera la entrada en los talleres a menores de 14 años. ${ }^{30} \mathrm{~A}$ su vez, se reclamaba la responsabilidad patronal en caso de incendio sobre los bancos y las herramientas. Durante estos años, los incendios de boliches eran bastante comunes, ya que los patrones solían asegurar su capital por más del doble del existente y, por ende, provocaban intencionalmente el incendio, destruyéndose en el siniestro las herramientas y banco del obrero, que no estaban asegurados. ${ }^{31}$ Por otra parte, el nivel de organización era muy alto: todos los días se repartían víveres y dinero para los más necesitados y muchos migraron al campo para emplearse en la cosecha de maíz. ${ }^{32}$ Por esta clase de medidas, los anarquistas no vacilaron en caracterizar la huelga como "pacífica, legalitaria”, criticando por elevación a los socialistas que allí activaban. ${ }^{33}$

A comienzos de abril, los ebanistas se vieron forzados a dividirse en dos categorías, según el poderío de las patronales donde trabajaban. De esta manera, se reanudó la actividad en las mueblerías de "segunda categoría" y la huelga

30. Ebanistas, carpinteros y anexos (12 de marzo de 1904). La Vanguardia.

31. Los bolicheros. Casos de incendio y sus perjuicios inmediatos (febrero de 1908). El Obrero En Madera. Sindicato de Obreros en Madera de la Capital Federal, Buenos Aires.

32. Las huelgas - Ebanistas (2 de abril de 1904). La Vanguardia.

33. Movimiento obrero (1 de abril de 1904). La Protesta. se volvió parcial contra aquellos patrones de "primera categoría" que no habían firmado las condiciones exigidas. ${ }^{34}$ Aunque no se hallaron criterios para esta subdivisión, se puede suponer que la primera aludía a las casas de muebles finos (Thompson, Maple, etc.) y la segunda a los boliches; en el gremio ebanista inglés, a finales del siglo XIX, existía una división similar, entre honourable y dishonourable houses (Reid, 1970, p. 33). En el caso de los boliches, si bien no se logró prohibir el trabajo a destajo, se acordó una jornada de nueve horas y $20 \%$ de aumento por pieza, además del seguro sobre bancos y herramientas y la prohibición de emplear menores y obreros no sindicalizados. La primera categoría, en cambio, prosiguió el paro durante más de tres meses y consiguió, al final, la abolición del trabajo a destajo. A fines de julio, el sindicato había arreglado condiciones con 293 fabricantes de ambas categorías, lo cual daba prácticamente por finalizado el movimiento. ${ }^{35}$ Esta victoria parcial afianzó la organización sindical, lo que posibilitó comenzar a publicar un periódico de forma regular, El Obrero Ebanista, en diciembre de aquel año, órgano de la renombrada "Sociedad de Obreros Ebanistas, Similares y Anexos", es decir, dejando afuera del gremio de forma explícita a los carpinteros.

Luego de la huelga de los ebanistas, en septiembre de 1904 fue el turno de los carpinteros de obra blanca; a comienzos de mes, paralizaron las labores en madera en las obras de construcción así como en las carpinterías mecánicas. Por la naturaleza de su actividad, esta huelga fue bastante distinta en ciertas dimensiones con respecto al movimiento que venían de realizar los ebanistas. En la industria de la

34. Las huelgas (9 de abril de 1904). La Vanguardia.

35. Las huelgas (23 de julio de 1904). La Vanguardia. 
construcción, los carpinteros se subdividían entre una mayoría "de obra blanca" (trabajos comunes) y una minoría "de obra fina", que requerían una calificación más elevada (Patroni, 1897). Los carpinteros de obra blanca trabajaban o bien para una empresa constructora (en muchos casos, los aserraderos-carpinterías mecánicas) o bien, lo que era más común, para un contratista que reclutaba la fuerza de trabajo. En su análisis, es importante notar que la actividad estaba directamente ligada con las bruscas oscilaciones coyunturales generadas por los ciclos económicos de especulación y auge inmobiliario, concomitantes al desarrollo urbano de la ciudad de Buenos Aires así como por sus respectivas fases de contracción y crisis (Poy, 2014, p. 30). Por otra parte, los obreros de la construcción se veían afectados por el clima y los días festivos. ${ }^{36}$ Si bien el universo laboral estaba teñido por la inestabilidad laboral y los accidentes, los oficiales carpinteros representaban otro eslabón difícil de reemplazar en ocasión de una huelga. Su función en las obras abarcaba la construcción propiamente dicha (estructuras y andamios, pisos, puertas, ventanas) así como las terminaciones (revestimientos, ornamentos). En términos productivos, las tareas se hallaban interconectadas con otros oficios de la construcción, como los albañiles $\mathrm{y}$ los yeseros.

Hacia septiembre 1904, dada la alta ocupación en la rama, se juzgó como una ocasión propicia para que los patrones accedieran a una jornada laboral de ocho horas. ${ }^{37}$ Durante el transcurso del paro, se realizaban múltiples reuniones a

36.Los obreros y el trabajo (26 de agosto de 1901). La Prensa. Biblioteca Nacional Mariano Moreno, Buenos Aires.

37. Movimiento obrero (15 de septiembre de 1904). La Protesta. diario en distintos puntos de la ciudad, establecidos como secciones del gremio (Belgrano, Flores, La Boca). ${ }^{38}$ Dado que, al igual que en otros conflictos laborales, los obreros vigilaban los talleres para desalentar a quienes fueran a trabajar, la policía comenzó a arrestar a quienes se encontraran en las cercanías. A mediados de octubre, llevando más de 48 días de huelga, la paralización de la actividad era casi total. ${ }^{39}$ Para sobrevivir materialmente en lo cotidiano, los huelguistas se empleaban en otras actividades y, además, recibían "donativos" de otras asociaciones gremiales y de particulares. A dos meses de iniciado el paro, los obreros aserradores de carpinterías mecánicas resolvieron plegarse a la medida, lo cual apuntaló al movimiento. ${ }^{40}$ En la misma dirección, los obreros albañiles discutieron explícitamente no dejar de producir con el fin de que se acumularan trabajos inconclusos, que debían finalizar los oficiales carpinteros. Hacia fines de noviembre, $105 \mathrm{pa}^{-}$ trones habían acordado el pliego de condiciones del gremio y la huelga general, por lo tanto, continuó de forma parcial contra quienes no lo hubieran hecho, definiendo descontar un peso a quienes volvieran a trabajar para sostener a los huelguistas. ${ }^{41}$ En los últimos días de 1904, la huelga continuaba, registrando más de cuatro meses de paro de actividades en la rama. ${ }^{42}$ A modo de cierre, dedicaremos las últimas páginas a indagar el conjunto de episodios y fac-

38. Movimiento obrero (11 de septiembre de 1904). La Protesta.

39. Carpinteros (25 de octubre de 1904). La Organización Obrera.

40. Las huelgas. Carpinteros y anexos (29 de octubre de 1904). La Vanguardia.

41. Las huelgas. Carpinteros (26 de noviembre de 1904). La Vanguardia.

42. La huelga de carpinteros (31 de diciembre de 1904). La Protesta. 
tores que precipitaron, a comienzos de 1905 , la militarización de la ciudad y una enérgica ofensiva sobre el movimiento obrero.

\section{E1 estado de sitio de 1905: fin y principio de la conflictividad}

Cuando el 4 de febrero de 1905 el gobierno de Manuel Quintana (1904-1906) decretó el estado de sitio, podría afirmarse que pocos se sorprendieron por el anuncio. Si bien el argumento principal era sofocar el alzamiento del partido radical (UCR) en la Capital Federal y algunas provincias, pronto quedó de manifiesto que su propósito central era otro. Las huelgas y movilizaciones del año anterior habían sido numerosas, contando un paro total de actividades en la ciudad de Buenos Aires el 1 y 2 de diciembre, convocado por anarquistas y socialistas. Aún estaba fresco el recuerdo de la militarización del conflicto en el mercado central de frutos así como, posteriormente, del área circundante al puerto de Buenos Aires (Marotta, 1960; Oddone, 1949). Del mismo modo, el ejército había recibido órdenes a comienzos de 1905 para garantizar la cosecha a través del funcionamiento de los ferrocarriles. En otros sectores, la conflictividad obrera había alcanzado altos niveles hacia fin de año, con destacados paros entre los carpinteros de la construcción, albañiles y zapateros.

A comienzos de 1905, al paro general maderero en la industria de la construcción, que duró más de cuatro meses, le siguió una huelga de los obreros aserradores de San Fernando, declarada el 19 de enero. ${ }^{43}$ La conflictividad laboral se contagió también dentro del gremio de los toneleros, organizado en la "Sociedad

43. Aserradores (4 de febrero de 1905). La Vanguardia.
Cosmopolita de Oficiales Toneleros". El primer día del nuevo año, los oficiales declararon una huelga que debió ser suspendida a las dos semanas, afirmando que los resultados acabaron siendo "contraproducentes" a causa de "la acción de crumiros", lo cual demostraría o bien que el grado de calificación necesaria en este oficio era menor que en el resto de la rama o bien que existía una facilidad mayor de encontrar reemplazantes. ${ }^{44}$ Distinta fue la suerte de la pequeña "Sociedad Obreros Escoberos", que declaró una huelga a fines de enero y a los pocos días logró que casi la totalidad de los patrones acordaran las condiciones solicitadas. ${ }^{45}$

En paralelo a estos conflictos en la rama maderera, los obreros del "Ferrocarril Sur", organizados en la poderosa Confederación Ferrocarrilera, declararon una huelga el 30 de enero para conquistar un aumento salarial y la reducción de la jornada laboral, logrando un fuerte acatamiento a la medida en una de las huelgas más importantes del período, que se extendió en todo el sur de la provincia de Buenos Aires. Entre los gremios solidarios con la huelga ferroviaria, Marotta (1960, p. 200) destaca a los aserraderos y los tapiceros. En estas circunstancias, bajo la excusa de sofocar el alzamiento radical del 4 de febrero, la declaración del estado de sitio frenó de forma abrupta el ascenso de la conflictividad laboral. La represión fue implacable: los periódicos y locales sindicales y políticos fueron clausurados, se prohibió el derecho de reunión y se multiplicaron las detenciones de los militantes más comprometidos, tanto anarquistas como socialistas. El ensañamiento principal por parte del gobierno y la llamada "opinión pública" se dirigió contra

44. Toneleros (15 de enero de 1905). La Protesta.

45. Obreros Escoberos (25 de enero de 1905). La Protesta. 
los anarquistas, titulados de "agitadores extranjeros" y perturbadores del orden social (Oved, 2013, p. 417).

En el mapa de las corrientes políticas, el estado de sitio agudizó las tensiones preexistentes entre anarquistas y socialistas y catalizó el proceso de diferenciación entre estos últimos y los sindicalistas. Para esta nueva corriente, si la orientación electoralista del PS obstaculizaba la lucha obrera y representaba una integración paulatina al régimen capitalista, el llamado a la "tranquilidad" por parte de la dirección socialista frente a la ofensiva represiva gubernamental significaba directamente una "traición" a la clase. ${ }^{46}$ Los sindicalistas convocaron a la FORA libertaria para realizar una huelga general, aún a sabiendas de que varios miembros de su dirección habían sido detenidos o deportados. No obstante, la reunión conjunta finalmente se realizó y fue abortada por la policía, que asaltó el local deteniendo a 22 militantes y frustrando el intento más cercano por tomar la iniciativa frente al estado de sitio (Marotta, 1960, p. 202).

Bajo el marco represivo, la mayoría de las redacciones de la prensa gremial y política se trasladaron a la capital uruguaya, incluyendo aquellas de los gremios en madera. En suma, con esta medida de carácter excepcional, el gobierno de Quintana logró retener el control de la situación y aplacar la actividad huelguística para el momento de la cosecha. Sin embargo, la ofensiva gubernamental no logró hacer desaparecer las causas económicas y sociales que alimentaban el malestar popular y, por lo tanto, luego de unos pocos meses de inacción, el movimiento obrero volvió a cobrar ímpetu con la finalización del estado de sitio, desarrollán-

46. Acción obrera (mayo de 1905). El Obrero Ebanista, 4. dose una nueva escalada de paros y conflictos laborales.

\section{Conclusiones}

En este artículo hemos recorrido la trayectoria organizativa y la dinámica de la conflictividad laboral de los distintos oficios dentro del sector de la madera y el mueble de la ciudad de Buenos Aires, entrelazando el estudio sobre las formas del proceso de trabajo con la inserción de las izquierdas. El análisis ha puesto de manifiesto, por un lado, las estrategias y propuestas de organización de cada corriente así como, por el otro, sus resultados en términos de estructuración sindical y confrontación huelguística, pareciendo prevalecer una estabilidad mayor en aquellos oficios más calificados; el ejemplo paradigmático sería el sindicato ebanista. En una visión general, la escalada huelguística 1903-1905 consolidó dos estilos de militancia y organización gremial en función de las heterogeneidades de ambientes laborales y procesos productivos, la importancia de las patronales y las diferencias entre las trayectorias de estructuración sindical, existiendo una dinámica huelguística específica que oponía en un extremo a los ebanistas y, en el otro, a los obreros aserradores, con una gama de posiciones intermedias del resto de los oficios.

Estas diferencias se plasmaron, en primer lugar, en el momento elegido para desarrollar movimientos generales: mientras que entre los más calificados, la temporada "alta" de trabajo comenzaba en marzo con un pico hacia julio, en los aserraderos el tiempo de abundancia de empleo coincidía en general con la época de la cosecha y, en el caso de la construcción, con el inicio de la primavera. 
En segundo lugar, el análisis indicó que aquellos oficios más calificados, como los ebanistas y los torneros, sostuvieron mecanismos de apoyo a los huelguistas, incluso pecuniarios, para mantener el paro; mientras que en el caso de los trabajadores con menor calificación, si bien también existieron "subsidios" a huelguistas, su reemplazo por crumiros y la mayor incidencia de los capitalistas del ramo sobre el aparato del Estado, condicionaban una dinámica huelguística donde la violencia y los enfrentamientos, sea con rompehuelgas, sea con la policía, eran casi inevitables.

Finalmente, la consecución de los objetivos tendía a ser total para los oficios más calificados mientras que, en el segundo conjunto, los conflictos podían llegar a extenderse durante meses, aunque ello no significara necesariamente una resolución positiva, como ocurrió en la huelga de la construcción de 1904.

Será motivo de próximas indagaciones profundizar la mirada sobre cómo impactó la evolución industrial y la maquinización entre las formas de organización gremial en los sitios laborales así como cuáles fueron las iniciativas que se dieron las corrientes de izquierda según cada oficio.

$$
\propto \ddot{e} \propto
$$

Recibido: 12-11-2018

Aceptado: 22-04-2019

Publicado: 04-12 -2019 


\section{Referencias bibliográficas}

Anapios, L. (2016). Prensa y estrategias editoriales del movimiento anarquista en la Argentina de entreguerras. Anuario del Instituto de Historia Argentina "Dr. Ricardo Levene", 16(2), e025. Recuperado de https:// www.anuarioiha.fahce.unlp.edu.ar/article/view/IHAe025/7927

Argentina. Dirección de Comercio é Industria (2015). Censo industrial y comercial de la República Argentina 1908-1914. Buenos Aires: Talleres Graficos del Ministerio de Agricultura.

Argentina. Comisión directiva del censo nacional (1916). Tercer Censo Nacional levantado el 10 de junio de 1914. Buenos Aires: Talleres gráficos de L.J. Rosso y cía.

Belkin, A. (2018). Sindicalismo revolucionario y movimiento obrero en la Argentina. De la gestación en el Partido Socialista a la conquista de la FORA (1900-1915). Buenos Aires: Imago Mundi.

Belini, C. (2017). Historia de la industria en la Argentina. Buenos Aires: Planeta.

Belini, C. y Korol, J. C. (2012). Historia económica de la Argentina en el siglo XX. Buenos Aires: Siglo XXI.

Bill, D. (2007). Descalificados. Proceso de trabajo y clase obrera en la rama gráfica (1890-1940). Buenos Aires: Razón y revolución.

Bilsky, E. (2011). La semana trágica. Buenos Aires: Razón y revolución.

Camarero, H. (2007). A la conquista de la clase obrera. Los comunistas y el mundo del trabajo en la Argentina, 1920-1935. Buenos Aires: Siglo XXI Iberoamericana.

Camarero, H. (2015). El Partido Socialista de la Argentina y sus espinosas relaciones con el movimiento obrero: un análisis del surgimiento y disolución del Comité de Propaganda Gremial, 1914-1917. Izquierdas, 22, 158-179. https://doi.org/10.4067/S0718-50492015000100007

Camarero, H. (2016). La cultura política comunista en la clase obrera argentina de entreguerras: prácticas, repertorios de organización y subjetividad militante. Anuario del Instituto de Historia Argentina " $D$ r. Ricardo Levene”, 16(2), e024. Recuperado de https://www.anuarioiha.fahce.unlp.edu.ar/article/view/ IHAe024

Camarero, H. y Ceruso, D. (2015). Una historia del sindicato de la madera: organización gremial e influencia de la izquierda en las luchas obreras, Buenos Aires, 1917-1943. el@ tina. Revista electrónica de estudios latinoamericanos, 13(50), 1-15.

Camarero, H. y Ceruso, D. (2016). Reflexiones sobre el vínculo entre movimiento obrero e izquierda en Argentina: el caso metalúrgico entre 1916 y 1943. Cuadernos de bistoria (Santiago), 44, 57-79.

Camarero, H. y Herrera, C. (2005). El Partido Socialista en Argentina. Sociedad, politica e ideas a través de un siglo. Buenos Aires: Prometeo. 
Caruso, L. (2016). Embarcados. Los trabajadores maritimos y la vida a bordo: sindicato, empresas y Estado en el puerto de Buenos Aires, 1889-1921. Buenos Aires: Imago Mundi.

Ceruso, D. (2015). La izquierda en la fábrica. La militancia obrera industrial en el lugar de trabajo, 1916-1943. Buenos Aires: Imago Mundi.

Ceruso, D. (2017). El Partido Socialista y la cuestión gremial. Debates internos durante la primera mitad de la década infame. Archivos de historia del movimiento obrero y la izquierda, 5(10), 119-139.

Darnton, R. (1984). La gran matanza de gatos y otros episodios en la historia de la cultura francesa. Buenos Aires: Fondo de Cultura Económica.

Díaz Alejandro, C. (1970). Ensayos sobre la historia económica argentina. Buenos Aires: Amorrortu.

Falcón, R. (1984). Los orígenes del movimiento obrero: 1857-1899. Buenos Aires: CEAL.

Fernández Cordero, L. (2015). The anarchist wager of sexual emancipation in Argentina, 1900-1930. En Laforcade, G. y Shaffer, K. In Defiance of Boundaries: Anarchism in Latin American History (pp. 302-325). Florida: University Press of Florida.

Gandolfo, R. (1992). Las sociedades italianas de socorros mutuos de Buenos Aires: cuestiones de clase y etnia dentro de una comunidad de inmigrantes (1880-1920). En Devoto, F. y Miguez, E. (Comps.), Asociacionismo, trabajo e identidad étnica. Los italianos en América latina en una perspectiva comparada. Buenos Aires: CEMLA-CSERIEHS.

Gerchunoff, P. y Llach, L. (2010). El ciclo de la ilusión y el desencanto. Un siglo de politicas económicas argentinas. Buenos Aires: Ariel.

Helguera, D. (1893). La producción argentina en 1892. Buenos Aires: Goyoaya y cía.

Koppmann, W. L. (2018). Orígenes, trayectoria organizativa y formas de estructuración sindical de los obreros de la madera y el mueble de la ciudad de Buenos Aires, 1889-1910. Estudios del trabajo, 55, 89-121.

Liernur, J. F. (2000). La construcción del país urbano. En Lobato, M. Z. (Ed.), Nueva Historia Argentina. Tomo V (pp. 409-463). Buenos Aires: Sudamericana.

Lizárraga, D. y Mason, C. (2016). Industria de la madera: conflictividad laboral y organización sindical en Buenos Aires, 1934-1940. Perspectivas sobre la industria, 3, 9-36.

Lobato, M. Z. (2001). La vida en las fábricas. Trabajo, protesta y politica en una comunidad obrera de Berisso (1904-1970). Buenos Aires: Prometeo Libros/Entrepasados.

Marotta, S. (1960). El movimiento sindical argentino. Su génesis y desarrollo. Tomo 1. Buenos Aires: Ediciones Lacio. 
Martínez Mazzola, R. (2011). La neutralidad como problema y como solución. La política gremial del Partido Socialista después de la ruptura sindicalista. Identidades, 1(1), 2-20.

Montgomery, D. (1979). Workers' control in America: studies in the history of work, technology, and labor struggles. Cambridge: Cambridge University Press.

Oddone, J. (1949). Gremialismo proletario argentino. Buenos Aires: La Vanguardia.

Oved, I. (2013). El anarquismo y el movimiento obrero en Argentina. Buenos Aires: Imago Mundi.

Patroni, A. (1897). Los trabajadores en la Argentina. Buenos Aires: La Vanguardia.

Poy, L. (2014). Los origenes de la clase obrera argentina. Huelgas, sociedades de resistencia y militancia politica en Buenos Aires, 1888-1896. Buenos Aires: Imago Mundi.

Poy, L. (2016). "Neutralistas" y "políticos". Los debates en el Partido Socialista argentino acerca de la relación entre partido y sindicato, 1901-1904. Avances del Cesor, 13(15), 19-38.

Poy, L. (2018). An early attempt at labor regulation in the Global South: the Argentine Ley Nacional del Trabajo of 1904 and the response of working-class organizations. Labor History, 59(5). DOI: 10.1080/ 0023656X.2019.1537023

Rapoport, M. y Seoane, M. (2007). Buenos Aires: historia de una ciudad, 1880-1955. Tomo 1. Buenos Aires: Planeta.

Reid, H. (1970). The furniture makers. A History of Trade Unionism in the Furniture Trade 1865-1972. Oxford: Malthouse Press.

Rocchi, F. (2006). Chimneys in the desert: industrialization in Argentina during the export boom years, 18701930. Stanford: Stanford University Press.

Rock, D. (2001). Argentina en 1914: Las Pampas, el interior, Buenos Aires. En J. Lynch R. Cortés Conde, E. Gallo, D. Rock, J. C. Torre y L. de Riz, Historia de la Argentina. Barcelona: Crítica.

Santillán, D. A. de (1927). La Protesta: su historia, sus diversas fases y su significación en el movimiento anarquista de América del Sur. Certamen Internacional de La Protesta en ocasión del 30 aniversario de su fundación. Buenos Aires: La Protesta.

Santillán, D. A. de (2005) [ed. orig. 1933]. La FORA. Ideologia y trayectoria del movimiento revolucionario en la Argentina. Buenos Aires: Proyección.

Scheinkman, L. (2016). Pequeños huelguistas: participación de menores en los conflictos de la industria del dulce en Buenos Aires en la primera década del siglo XX. Trashumante. Revista Americana de Historia Social, (8), 108-130.

Schvarzer, J. (1996). La industria que supimos conseguir. Buenos Aires: Planeta. 
Suriano, J. (2001). Anarquistas. Cultura y politica libertaria en Buenos Aires, 1890-1910. Buenos Aires: Manantial.

Tilly, C. (1995). Popular Contention in Great Britain, 1758-1834. Cambridge: Harvard University Press.

Tortti, C. (2007). El viejo partido socialista y los orígenes de la nueva izquierda. La Plata: Universidad de La Plata.

Villalba, R. (2010). Historia del Sindicato de la Madera de Capital Federal (en el contexto del movimiento obrero Argentino). Buenos Aires: Dunken.

Yujnovsky, O. (1983). Del conventillo a la villa miseria. En Romero, J. L. y Romero, L. A. (Eds.), Buenos Aires, historia de cuatro siglos. Buenos Aires: Editorial Abril. 